\title{
Healthcare Policy: Federally Mandated Insurance Coverage for Infertility Treatment
}

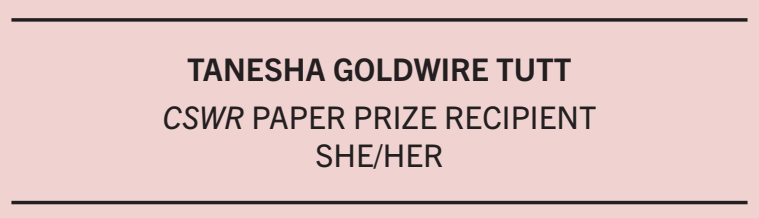

Approximately 15\% of couples in the United States (U.S.) suffer from infertility. Existing infertility treatments and alternate paths to parenthood, such as adoption, are available but financially inaccessible and require self-payment. Although organizations such as the American Medical Association (AMA) and World Health Organization (WHO) classify infertility as a disease, the U.S. has not federally mandated insurance coverage for infertility. Currently, only 15 states require insurance companies to offer some type of fertility benefit and these requirements vary across states.

This paper discusses the need to federally mandate insurance coverage for infertility in the U.S. Infertility not only causes devastating outcomes for individual families, but affects nearly all demographics across the world. However, national legislation on infertility coverage continues to fail the many couples who suffer from this condition. The paper concludes with implications for social work practice and recommends ways social workers can support this policy movement. Social workers have an ethical duty not only to address clients' mental and emotional needs, but also to be at the frontlines of policy and to advocate for federal insurance coverage for clients who desperately want to realize their dream of conceiving a child.

Keywords: fertility, infertility, insurance coverage, insurance, in vitro fertilization (IVF) 


\section{POSITIONALITY STATEMENT}

I write from the positionality of an individual who has had personal experience with infertility. As a cisgender woman, I know what it is to face the reality that conceiving a child is a privilege, and that not everyone will know the joy of pregnancy through heterosexual intercouse. I know what it is to grieve over the unmet expectation of bearing a child. The mental, emotional, physical, and financial strain my husband and I experienced seemed unreal, unfair, and unfathomable. The level of bias, discrimination, and sometimes ignorance we encountered while trying to navigate our infertility was unbelievable.

I also write from a positionality of privilege as a cisgender woman in a heterosexual relationship. Our diagnosis forced me, my husband, and those in our circle to confront our own ignorance. We were guilty of "meddling" in others' fertility, failing to consider that a person or couple may not have had a choice in either delaying or forgoing starting a family. We also had to confront our own bias, as we were conditioned to believe that only women could suffer from infertility. Feeding into gender binary viewpoints, I dismissed the idea that LGBGTQIA+ couples and individuals also face the pain and demoralization that infertility can cause.

Finally, I write from the positionality of a minority. While I speak as a person of privilege in terms of my sexual and gender identity as a heterosexual cisgender woman, I am a Black woman married to a Black man. I understand what it is to be stigmatized and marginalized when trying to access infertility treatment and financial support. I witnessed firsthand the privilege that exists for white women, white men, and white couples who are afforded opportunities and access to fertility treatments that are not available to those of other races and ethnicities. I realized that social constructs narrowly define who can be impacted by infertility, who is deserving of support, and who should have access to various types of treatments, coverage, and care.

This article reflects a gender binary point of view and focuses on those who are cisgender, and in that way it is indicative of the lack of research that exists on other populations that may be dealing with infertility. As a person of fertility privilege and disenfranchisement, I can identify with those in both categories. The experiences of being dismissed, unheard, and unrecognized fueled my passion to write this article, in hopes that it would generate awareness of infertility, its effects, and the need to advocate for changes in laws and policies that marginalize those who are suffering with the disease.

\section{HEALTHCARE POLICY: FEDERALLY MANDATED INSURANCE COVERAGE FOR INFERTILITY TREATMENT}

In 2020, UCLA Health reported that approximately $15 \%$ of couples will struggle with infertility (UCLA Health, 2020). According to MedlinePlus (n.d.), infertility is the inability to become pregnant after 12 months of trying to conceive and includes miscarriages and stillbirths. Despite the WHO and the AMA classifying infertility as a disease, there is no federally mandated insurance coverage for infertility treatment (Insogna \& Ginsburg, 2018; Strauss, 2018).

For many couples around the world, having a baby is a critical step to building a family. For both the person trying to conceive and their partner, a diagnosis of infertility can lead to many challenges such as anger, depression, sexual dysfunction, divorce, and social isolation (Deka \& Sarma, 2010). Given the prevalence of infertility, its underrecognized status as a disease that warrants coverage, and the high costs people pay to exercise their right to conceive a child, federally mandated insurance policies are a vital but missing component of our nation's healthcare landscape.

\section{THE SOCIAL PROBLEM}

In the U.S., at least one in eight couples will experience infertility (RESOLVE, 2019). Among married couples, about 7\% of women and $16 \%$ of men, ranging in age from 15-44, are classified as infertile (Centers for Disease Control [CDG], 2016; Chandra et al,, 2013). Infertility is typically viewed as a female condition, but in approximately $40 \%$ to $50 \%$ of infertility cases, the male is the factor leading to infertility 
(Kumar \& Singh, 2015). Infertility can be treated with medication, surgery, intrauterine insemination (IUI), or assisted reproductive technologies (ARTs) such as in vitro fertilization (IVF). These fertility treatments involve extracting eggs and embryos from a female and either combining them with sperm in a laboratory and reinserting into the body, or donating them to another woman (CDC, 2019). Each treatment comes with its own costs, risks, and rates of success.

\section{DISPROPORTIONATE IMPACTS ON MARGINALIZED POPULATIONS}

The medical definition of infertility is the "inability of couples to conceive after at least 1 year of having sex without using birth control methods" (U.S. National Library of Medicine, 2019, para 1). This definition limits those capaable of experiencing infertility to heterosexual couples that have intercourse. It assumes that only men and women try to have children, and also focuses on women's bodies instead of men's. However, men and same sex-couples need support with infertility, too. The current definition of infertility fails to address the inclusiveness needed to ensure all populations can receive equal and adequate access to support and care for infertility and leaves room for interpretation of who does and does not deserve access to care.

Much of the research, advocacy, and support for infertility focuses on white, heterosexual women (Shreffler et al., 2017). Although African American, Chinese, and Latine couples have higher rates of infertility than white couples, they are less likely to seek treatment (Inhorn \& Patrizio, 2018; Insogna \& Ginsbury, 2019). According to a study published in Health Psychology, "heterosexual white women are twice as likely as racial or sexual minority women to obtain medical help to get pregnant" (Blanchfield \& Patterson, 2015, p. 575). The study further explains that a cause for this lack of pursuing treatment a lack of health insurance. Moreover, as of 2018, Blacks are still 1.5 times as likely as whites to be uninsured (Ariga et al., 2020).

Blanchfield and Patterson (2015) found that in studies conducted in 2002 and again from 2006 to 2010, 13\% of white heterosexual women received assisted reproductive medical support, while only $7 \%$ of minority heterosexual women and white sexual minority women received support. Furthermore, only $1 \%$ of women who identified as both racial and sexual minorities were found to have received such support. Men were not included in the study, speaking to the gap in the literature on infertility in men. Feinberg and colleagues (2005) found that when African Americans had access to healthcare through partial insurance, there was a $400 \%$ increase in their utilization of ARTs. Yet even with access, minority patients had poorer health outcomes than white patients, including higher spontaneous abortions, lower clinical pregnancy rates, and lower live births (Insogna \& Ginsbury, 2019). Thus, even with lower successful outcome rates, minorities clearly benefit from having insurance to cover infertility treatments.

\section{BARRIERS TO ACCESSING TREATMENT}

In addition to its widespread impact and disproportionate effects on marginalized groups, infertility warrants insurance coverage. However, inconsistent nationwide coverage policies have created major cost burdens for individuals. In 1948, the United Nations Universal Declaration of Human Rights stated that every person has a right to start a family, and in 2015, the American Society of Reproductive Medicine (ASRM) Ethics Committee stated that "reproduction is a fundamental interest and human right" (2015). However, U.S. legislation has failed to recognize that infertility is a disease that denies people the basic human right of conceiving a child. Additionally, while the WHO and AMA classify infertility as a disease, many insurance companies in the U.S. do not cover infertility and erroneously view infertility treatment as experimental medicine (Strauss, 2018). This label neglects the substantial body of research highlighting that procedures to address infertility, such as egg freezing, are no longer experimental and ARTs, such as IVF, have increased in success with as many as 8 million babies being born through IVF in 2018 (Dunne \& Roberts, 2016; Strauss, 2018).

Without federal assistance, individual states bear the responsibility to determine how to regulate infertility coverage (American Society 
of Reproductive Medicine [ASRM] Ethics Committee, 2015, para 5; National Conference of State Legislature [NCSL], 2019; Universal Declaration of Human Rights, 1948). Currently, 19 states have infertility coverage laws that require insurance companies to either cover or offer infertility treatments as part of the policy (RESOLVE, 2020; NCSL, 2019) (see Table 1). Of those 19 states, 13 have comprehensive coverage for costs associated with IVF, and 10 have fertility preservation laws (RESOLVE, 2020) (see Table 1). However, coverage may not exist for other ART treatments and associated medications (Insogna \& Ginsburg, 2018).

Four states (Georgia, Michigan, Minnesota, and New Mexico) offer one Medicaid plan to diagnose infertility, but do not mandate any level of coverage for infertility treatment (Weigel et al., 2020.) Of the states listed in Table 1, Massachusetts, New Hampshire, and New York offer this same benefit, but New York is the only state that requires Medicaid coverage to treat infertility (Weigel et al., 2020). Thus, most individuals with government insurance (state or federal) have no coverage for infertility treatments and are given no choice but to personally cover all fees associated with any ARTs (RESOLVE, 2018).

White, McQuillan, and Greil (2006) found that many physicians may hold biases about who should and should not receive infertility treatment. Without federally mandated infertility coverage, states and providers can personally define infertility and determine who receives treatment (ASRM Ethics Committee, 2015). Giving physicians power to determine who receives treatments creates an indirect and subtle--but deeply harmful--form of ethnic cleansing. Consequently, the medical field risks prioritizing communities with privilege in the provision of access. This system enables racism, ableism, transphobia, and many other forms of oppression to influence decisions of who can conceive. The subjective selection of those receiving infertility treatment promotes privilege and creates a system in which those from specific racial, ethnic, gender, and socioeconomic communities are denied access to insurance coverage and medical procedures that are critical to being able to have a baby.

\section{TABLE 1. STATES WITH INFERTILITY INSURANCE BENEFITS}

\begin{tabular}{|c|c|c|c|}
\hline States & $\begin{array}{l}\text { States with infertility } \\
\text { insurance laws }\end{array}$ & $\begin{array}{l}\text { States with IVF } \\
\text { insurance laws }\end{array}$ & $\begin{array}{l}\text { States with fertility } \\
\text { preservation laws }\end{array}$ \\
\hline Arkansas & $x$ & $x$ & \\
\hline California & $x$ & & $x$ \\
\hline Colorado & $x$ & $x$ & $x$ \\
\hline Connecticut & $x$ & $x$ & $x$ \\
\hline Delaware & $x$ & $x$ & $x$ \\
\hline Hawaii & $x$ & $x$ & \\
\hline Illinois & $x$ & $x$ & $x$ \\
\hline Louisiana & $x$ & & \\
\hline Maryland & $x$ & $x$ & $x$ \\
\hline Massachusetts & $x$ & $x$ & \\
\hline Montana & $x$ & & \\
\hline New Hampshire & $x$ & $x$ & $x$ \\
\hline New Jersey & $x$ & $x$ & $x$ \\
\hline New York & $x$ & $x$ & $x$ \\
\hline Ohio & $x$ & & \\
\hline Rhode Island & $x$ & $x$ & $x$ \\
\hline Texas & $x$ & & \\
\hline Utah & $x$ & $x$ & \\
\hline West Virginia & $x$ & & \\
\hline \multicolumn{4}{|c|}{ From “Infertility coverage by state," by RESOLVE, 2020} \\
\hline (https://resolve.org/wl & -my-options/insuran & overage/inferti & coverage-state/) \\
\hline
\end{tabular}


Without consistent coverage, the costs of treatment far exceed what many couples can afford. In 2018, the average cost for infertility treatments, such as IVF, was $\$ 12,000$, but some couples paid over $\$ 22,000$ for one IVF cycle, depending on the types of medication needed to prepare for the treatment (Leonhardt, 2019; Strauss, 2018). In engaging in IVF, $71 \%$ of women who completed an IVF cycle were not covered by insurance (Leonhardt, 2019). Many couples spend the money fully aware that an unsuccessful fertilization could mean a loss of $\$ 12,000$ and potential cost an additional $\$ 12,000$ to try again. According to a 2017 article by Robert Kiltzman, the cost of a successful delivery from IVF in California was $\$ 112,799$, and the cost of other paths to parenthood, such as adoption, can cost around $\$ 30,000$ minimum. These are out-of-pocket funds that the average person likely does not have. The cost to treat infertility, coupled with a lack of insurance coverage for this disease, leaves many couples either struggling to fund treatment or giving up on having a baby altogether.

\section{THE SOCIAL POLICY RESPONSE}

Although there are states that do require some type of infertility insurance coverage, the Federal Employee Retirement Income Security Act exempts companies who engage in self-insurance (i.e., the companies pay medical claims themselves) from having to comply with state mandates (RESOLVE, 2018). This means that even in the states that do have some form of a mandate, people may still struggle to have their infertility treatments covered. Some companies and providers use the medical definition of infertility to justify their inadequate infertility policies. In her interview with physicians and top executives from both United Healthcare and Aetna, Fairyington (2015) highlighted that policies do not provide a pregnancy benefit but a benefit to those who meet the medical, evidence-based definition of infertility.

It is the biased interpretation of how infertility should be defined that disenfranchises many groups. Some state policies deny fertility support to parties that cannot necessarily meet the guidelines for infertility because they may not have engaged in 12 months of heterosexual intercourse without success in forming an embryo (including single men, single women, and LGBTQIA+ couples) (ASRM Ethics Committee, 2015; Weigel et al., 2020). For benefits, such as fertility preservation, an individual would have to have suffered from an iatrogenic condition--that is, infertility that resulted directly or indirectly from a healthcare provider performing a medical procedure (i.e. surgery) or treating a medical condition (i.e. use of radiation) (Campo-Engelstein, 2010). While it would seem that this would apply to transgender individuals receiving mendical care, gender-affirming medical and surgical treatments are not consider iatrogenic conditions (Weigel et al., 2020). Additionally, some insurance companies exclude coverage for all men, both single and married, as women are traditionally viewed as the main factor in infertility (Dupree, 2016).

\section{A CASE FOR FEDERALLY MANDATED INSURANCE}

Federally mandated insurance is essential to ensuring that infertility is recognized and treated as a disease. This mandate would open the door for social workers to advocate for marginalized groups, such as LGBTQ+ couples and men, ensuring that insurance policies do not exclude certain groups on the basis of society's definition of who can or cannot experience infertility. Two previously introduced pieces of legislation would require all insurance companies to mandate coverage for infertility treatments: the Family Building Act $(2009,2007,2003,2005)$ and the Medicare Infertility Coverage Act (2005, 2003). The Family Building Act of 2009 stipulated that all healthcare plans should offer infertility treatment benefits (Family Building Act, 2009; Holtzman, 2013). The Medicare Infertility Coverage Act of 2005 was an amendment to Medicare aimed at covering infertility treatments for those entitled to the benefit because of a disability (Holtzman, 2013; US Government Publishing Office, 2005).

Two other major pieces of legislation, the Patient Protection Act and the Affordable Care Act, expanded health care, but neither addressed the issue of coverage for infertility treatments. The idea of infertility as a disability was introduced in 1998 with Bragdon v. Abbott, during which 
the Supreme Court ruled that reproduction was "a major life activity" that should be protected under the Americans with Disabilities Act (Hawkins, 2007, p. 209). However, the ruling only ensured employers could not discriminate against an individual based on infertility and did not expand the mandate to cover infertility in company insurance plans. Consequently, insurance companies could still promote ableism by denying coverage to those physically unable to conceive through heterosexual intercourse. While the Patient Protection and Affordable Care Acts expanded health care, these laws did not address the issue of coverage for infertility treatments (Norris, 2020). Unfortunately, both the Family Building Act and the Medicare Infertility Coverage Act never made it to Congress for a vote.

Opponents of federally mandated infertility treatment coverage have argued that covering infertility treatments would come at a high cost. Yet, data from Massachusetts, Connecticut, and Rhode Island indicate that state-mandated infertility coverage does not significantly raise premiums. In the 30 years these states have been mandating infertility coverage, the cost is less than $1 \%$ of total premium costs (EMD Serono 2019; Wigel et al., 2020). Another argument is the social cost of infertility treatments. Those able to conceive through intercourse are reluctant to bear the costs of treatment for those who experience infertility (Hawkins, 2007). However, the very nature of health insurance demands that individual clients pay for treatments that they themselves may never receive. Though an individual client may never struggle with infertility, or for that matter, heart disease or cancer, insurance companies have always collected payments from these clients to ensure a large pool of resources. The barrier to federally mandated coverage encourages a system where groups are marginalized and systematically robbed of the right to become parents. However, until legislation is in place, many couples struggling with infertility must apply for grants and loans or use personal funds to assist themselves in becoming parents.

\section{IMPLICATIONS FOR SOCIAL WORK PRACTICE}

As social workers, supporting couples with infertility can be challenging given the lack of federally mandated insurance coverage for infertility treatment. With the distress that a diagnosis of infertility may cause, social workers may face the difficult task of helping clients find viable options for conceiving a child or accepting the reality that parenthood may not be possible. In 2007, the National Association of Perinatal Social Workers introduced standards for social work provision in infertility treatment centers to assist social workers helping clients navigate the mental, emotional, physical, and financial demands of infertility. Supporting couples experiencing infertility can be challenging given the dearth of policies that legitimize infertility as a disease, as well as the groups of people infertility can impact.

In 1987, obstetrician-gynecologist (OBGYN) social worker Sima K. Needleman recognized that social workers would play an integral role in supporting clients dealing with infertility. In her article, Needleman (1987) describes the psychosocial impact of infertility.including the trauma that could result from learning of infertility and the emotions often associated with trying to decide how or even if to move forward with pursuing alternate paths to parenthood. While the therapeutic responsibility of the social worker is vital to improving the mental and emotional well-being of the client, "infertility is not only a medical and emotional dilemma; in many ways it is also a social problem" (Needleman, 1987, p.136). Social workers must think beyond therapy to being advocates for clients facing infertility.

Given the lack of recognition around infertility as a disease, one of the key ingredients in advocating for policy change surrounding infertility is redefining infertility for lawmakers and insurance companies. For example, social workers may spread awareness of how psychologically damaging the experience of infertility can be. A study of 200 couples undergoing fertility treatments found that approximately $50 \%$ of women and $15 \%$ of men stated that infertility was the most devastating experience of their lives (Freeman et al., 1985). 
Social workers can advocate for policies that motivate or even incentivize insurance companies to recognize infertility as a disease and to provide coverage for infertility treatment, which can give a sense of hope to those who might see no other path to parenthood. Federally mandated insurance coverage would allow those individuals to undergo treatment for infertility without having to worry about significant out-ofpocket expenses. Policies offering incentives for companies that provide support for alternatives, such as adoption, may increase the number of organizations that will provide funding, so individuals can realize their dreams of becoming parents. Demonstrating how becoming a parent helps improve the emotional and mental well-being of a client may be critical in changing the minds of lawmakers at all levels.

\section{CONCLUSION}

Misconceptions about conception abound: that conceiving a child is an easy process, that only heterosexual couples can conceive, that problems with fertility originate with women, and that all child-free couples are child-free by choice. In contrast, few are aware that numerous individuals wake up every morning questioning their existence because they are unable to conceive a child naturally, a dream so central to their sense of personhood and identity. In addition, few healthcare providers and lawmakers realize the discriminatory effects of one-dimensional definitions of fertility and reproduction. If society understood the circumstances beyond peoples' control that lead to infertility, then we could collectively embrace the reality that infertility is a disease and those suffering from it need the same level of care and support as those suffering from other diseases.

Society must recognize that regardless of race, class, sexual orientation, or gender, any person may one day find that they are infertile. This public awareness is the first step to establishing universal laws and policies that federally mandate coverage for infertility treatments and accelerating conversations that aim toward deconstructing a system that alienates certain groups from receiving the treatment and care necessary to start a family. This deconstruction includes reimagining the current definitions used to identify who qualifies for fertility treatments and infertility coverage. Social work practitioners are critical to helping those with infertility overcome mental and emotional trauma. As such, they can be catalysts for changing narratives about infertility by highlighting systems of privilege at work in denying some the right to parenthood. Social workers are often voices for the voiceless and should be the leading advocates for federal laws and policies that promote equality and equity in infertility insurance coverage. Everyone deserves the chance to build a family.

\section{REFERENCES}

Blanchfield, B. V., \& Patterson, C. J. (2015). Racial and sexual minority women's receipt of medical assistance to become pregnant. Health Psychology, 34(6), 571.

Campo-Engelstein, L. (2010). For the sake of consistency and fairness: Why insurance companies should cover fertility preservation treatment for iatrogenic infertility. Cancer treatment and research, 156, 381-388. https://doi.org/10.1007/978-1-44196518-9_29

Centers for Disease Control. (2019). What is assisted reproductive technology? https://www.cdc.gov/art/whatis.html

Centers for Disease Control. (2016). Infertility. https://www.cdc.gov/nchs/fastats/ infertility.htm

Chandra, A., Copen, C. E., \& Stephen, E. H. (2013). Infertility and impaired fecundity in the United States, 1982-2010: Data from the National Survey of Family Growth. National Health Statistics Report, 14(67) 1-18. https://www.ncbi.nlm.nih.gov/ pubmed/24988820

Deka, K. P., \& Sarma, S. (2010). Psychological aspects of infertility. British Journal of Medical Practitioner, 3(3), 336. https://www.bjmp.org/content/psychological-aspectsinfertility

Dunne, C. \& Roberts, J. (2016). Social egg freezing: A viable option for fertility preservation. British Columbia Medical Journal, 58(10), 573-577. https://bcmj.org/ articles/social-egg-freezing-viable-option-fertility-preservation

Dupree, J. M. (2016). Insurance coverage for male infertility care in the United States. Asian Journal of Andrology, 18(3), 339-341. https://doi.org/10.4103/1008682X.177838

EMD Serono. (2019). Employers and Evidence-Based Infertility Benefits: A guide to making informed decisions. http://familybuilding.resolve.org/site/DocServer/ employers-and-evidence-based-infertility-benefits.pdf?docID $=10584$ 
Ethics Committee of the American Society for Reproductive Medicine. (2015). Disparities in access to effective treatment for infertility in the United States: An Ethics

Committee opinion. Fertility \& Sterility, 104(5), 1104-1110. https://www.fertstert.org/ article/S0015-0282(15)01650-7/fulltext

Family Building Act of 2009, S. 1258, 111 th Cong. (2009). https://www.congress.gov/ bill/111th-congress/senate-bill/1258/text

Fairyington, S. (2015). Should same-sex couples receive fertility benefits? The New York Times. https://well.blogs.nytimes.com/2015/11/02/should-same-sex-couplesreceive-fertility-benefits/

Feinberg, E. V., Larsen, F. W., Catherino, W. H., Zhang, J., \& Armstrong, A.Y. (2005) Comparison of assisted reproductive technology utilization and outcomes between Caucasian and African American patients in an equal-access-to-care-setting. Fertility and Sterility, 85(4), 888-894. https://doi.org/10.1016/j.fertnstert.2005.10.028

Freeman, E. W., Boxer, A. S., Rickels, K., Tureck, R., \& Mastroianni Jr, L. (1985). Psychological evaluation and support in a program of in vitro fertilization and embryo transfer. Fertility and Sterility, 43(1), 48-53.

Gleicher, N. (2018). Expected advances in human fertility treatments and their likely translational consequences. Journal of Translational Medicine, 16(1), 149. https:// doi.org/10.1186/s12967-018-1525-4

Hawkins, J. L. (2007). Separating fact from fiction: Mandated insurance coverage of infertility treatments. Washington University Journal of Law and Policy, 23, 203-228. https:/ / openscholarship.wustl.edu/cgi/viewcontent.cgi?article=1337\&context=law_ journal_law_policy

Holztman, J. (2013). Infertility: A plague gone unnoticed. Stanford Journal of Public Health. https://web.stanford.edu/group/sjph/cgi-bin/sjphsite/infertility-a-plaguegone-unnoticed/

Inhorn, M. C., \& Partizio, P. (2018). Is lower quality clinical care ethically justifiable for patients residing in areas with infrastructure deficits? AMA Journal of Ethics, 20(3), 228-237. https://doi.org/10.1001/journalofethics.2018.20.3.ecas1-1803

Insogna, I. G., \& Ginsburg, E. S. (2018). Infertility, inequality, and how lack of insurance coverage compromises reproductive autonomy. AMA Journal of Ethics, 20(12), E1152-1159. https://doi.org/10.1001/amajethics.2018.1152

Kiltzman, R. (2017). How much is a child worth? Providers' and patients' views and responses concerning ethical and policy challenges in paying for ART. PLOS One, 12(2), e0171939. https://doi.org/10.1371/journal.pone.0171939

Kumar, N., \& Singh, A. K. (2015). Trends of male factor infertility, an important cause of infertility: A review of the literature. Journal of Human Reproductive Science, 8(4), 191-196. https://doi.org/10.4103/0974-1208.170370
Leonhardt, M. (2019, August 13). Women are traveling far and wide for affordable IVFhere's why it's so expensive. CNBC. https://www.cnbc.com/2019/08/13/womenare-traveling-far-and-wide-for-affordable-ivf.html

Livingston, G. (2018, July 17). A third of U.S. adults say they have used fertility treatments or know someone who has. Pew Research Center. https://www.pewresearch.org/ fact-tank/2018/07/17/a-third-of-u-s-adults-say-they-have-used-fertility-treatmentsor-know-someone-who-has/

Medline Plus. (2019). Infertility. https://medlineplus.gov/ency/article/001191.htm

Medline Plus. (n.d.). Infertility. https://medlineplus.gov/infertility.html

National Conference of State Legislatures. (2019). State laws related to insurance coverage for infertility treatment. http://www.ncsl.org/research/health/insurancecoverage-for-infertility-laws.aspx

Needleman, S. K. (1987). Infertility and in vitro fertilization: The social worker's role. Health and Social Work, 12(2), 135-142.

RESOLVE. (2020). Infertility coverage by state. https://resolve.org/what-are-myoptions/insurance-coverage/infertility-coverage-state/

RESOLVE. (2019). Fast facts. https://resolve.org/infertility-101/what-is-infertility/fastfacts/

RESOLVE. (2018). Health insurance 101. https://resolve.org/what-are-my-options/ insurance-coverage/health-insurance-101/

Shreffler, K.M., Greil, A.L., \& McQuillan, J. (2017). Responding to infertility: Lesson from a growing body of research and suggested guidelines for practice. Family Relationships, 66(4), 644-656. doi: 10.1111/fare.12281

Strauss, E. (2018). 40 years later, why is IVF still not covered by insurance? Economics, ignorance, and sexism. https://www.cnn.com/2018/07/25/health/ivf-insuranceparenting-strauss/index.html

The National Association of Perinatal Social Workers. (2007). Standards for social work services in infertility treatment centers offering assisted reproductive technologies and the use of donor gametes [PDF]. https://www.napsw.org/assets/docs/infertilitystandards.pdf

UCLA Health. (2020). Infertility. http://obgyn.ucla.edu/infertility

Universal Declaration of Human Rights. (1948). https://www.ohchr.org/EN/UDHR/ Documents/UDHR_Translations/eng.pdf

U.S. Government Publishing Office. (2005). H.R.2758 (IH)- Medicare Infertility Coverage Act of 2005. https://www.govinfo.gov/app/details/BILLS-109hr2758ih 
Weigel, G., Ranji, U, Long, M., and Salganicoff, A. (2020). Coverage and use of fertility services in the U.S.. https://www.kff.org/womens-health-policy/issue-brief/coverageand-use-of-fertility-services-in-the-u-s/

White, L., McQuillan, J., \& Greil, A.L. (2006). Explaining disparities in treatment seeking: the case of infertility. Fertility and Sterility, 85(4), 853-857.
TANESHA GOLDWIRE TUTT (she/her) graduated in 2020 with a Masters of Science in Social Work from Columbia School of Social Work concentrating in Advanced Clinical Social Work Practice. Tanesha holds a Bachelor of Science in both

English and Communication, as well as a Masters of Science in Communications from Florida State University. She also holds a Doctorate in Health Education from A.T. Still University. She currently works on the federal level as a public health advisor in Atlanta, GA. 